\title{
CDCA5 promotes the progression of prostate cancer by affecting the ERK signalling pathway
}

\author{
JUNPENG JI ${ }^{1,2^{*}}$, TIANYU SHEN ${ }^{1,3^{*}}$, YANG LI ${ }^{1 *}$, YIXI LIU ${ }^{1}$, ZHIQUN SHANG ${ }^{1}$ and YUANJIE NIU ${ }^{1}$ \\ ${ }^{1}$ Tianjin Institute of Urology, The Second Hospital of Tianjin Medical University, Hexi, Tianjin 300211; \\ ${ }^{2}$ Department of Urology, The Third Affiliated Hospital, College of Clinical Medicine of Henan University of Science \\ and Technology, Luoyang, Henan 471003; ${ }^{3}$ School of Medicine, Nankai University, Tianjin 300071, P.R. China
}

Received July 17, 2020; Accepted November 9, 2020

DOI: $10.3892 /$ or.2021.7920

\begin{abstract}
Cell division cycle-associated 5 (CDCA5) can regulate cell cycle-related proteins to promote the proliferation of cancer cells. The purpose of the present study was to investigate the expression level of CDCA5 in prostate cancer $(\mathrm{PCa})$ and its effect on PCa progression. The signalling pathway by which CDCA5 functions through was also attempted to elucidate. Clinical specimens of PCa patients were collected from the Second Hospital of Tianjin Medical University. The expression level of CDCA5 in cancer tissues and paracancerous tissues from PCa patients was detected by RT-qPCR analysis and IHC. The relationship between the expression level of CDCA5 and the survival rate of PCa patients was analysed using TCGA database. Two stable cell lines (C4-2 and PC-3) with CDCA5 knockdown were established, and the effects of CDCA5 on PCa cell proliferation were detected by MTT and colony formation assays. Flow cytometry was performed to detect the effect of CDCA5 on the PCa cell division cycle, and western blot analysis was used to determine changes in ERK phosphorylation levels after CDCA5 knockdown. The effect of CDCA5 expression on prostate tumour growth was assessed using a mouse xenograft model. The results revealed that the mRNA and protein expression levels of CDCA5 were significantly higher in PCa tissues than in paracancerous tissues. High CDCA5 expression was associated with the prognosis of patients with PCa. CDCA5 expression knockdown significantly reduced the number of PCa cells in mitoses and inhibited their proliferation in vitro and in vivo. When CDCA5 was knocked down, the phosphorylation level of ERK was also reduced. Collectively, CDCA5 was upregulated and affected the prognosis of patients with PCa. Decreased CDCA5
\end{abstract}

Correspondence to: Dr Zhiqun Shang and Dr Yuanjie Niu, Tianjin Institute of Urology, The Second Hospital of Tianjin Medical University, 23 Pingjiang Road, Hexi, Tianjin 300211, P.R. China

E-mail: urologyszq@sina.com

E-mail: urologynyj@163.com

${ }^{*}$ Contributed equally

Key words: prostate cancer, cell division cycle-associated 5, extracellular signal-regulated kinase, cell proliferation, cell cycle expression inhibited PCa cell proliferation by inhibiting the ERK signalling pathway. Thus, CDCA5 may be a potential therapeutic target for PCa.

\section{Introduction}

Prostate cancer $(\mathrm{PCa})$ is a genitourinary malignancy that threatens the health of men worldwide. In Europe and the United States, the incidence (19\%) of PCa ranks first among male malignant tumours, and its mortality (9\%) ranks second $(1,2)$. Currently, the incidence of PCa in China has surpassed that of bladder cancer to rank first among male genitourinary tumours. For PCa treatment, surgery and chemotherapy are currently used. Surgical treatment is expensive and causes a certain degree of inconvenience to patients. Moreover, the therapeutic effects of existing targeted drugs are unsatisfactory. To improve the therapeutic effect of targeted drugs, it is particularly important to explore the aetiology of $\mathrm{PCa}$ development. Only by clarifying the pathogenesis of $\mathrm{PCa}$ can we find specific molecular markers for use as predictors and therapeutic targets.

The cell division cycle-associated 5 (CDCA5) gene encodes the CDCA5 protein, which is a major regulator of sister chromatid cohesion and segregation (3). CDCA5 maintains sister chromatid cohesion by stabilizing the cohesive complex, and it ensures accurate cell chromosome separation during meiosis and mitosis; it also plays an essential role in DNA repair (4). Moreover, CDCA5 regulates the activity of cell cycle-associated proteins and transcription factors, thereby promoting proliferation and participating in apoptosis in cancer cells (5). Studies have reported that high expression of the CDCA5 gene is closely related to the incidence of bladder (6), lung (7), liver $(8,9)$ and colorectal cancer (10). Notably, researchers have concluded through bioinformatics analysis that CDCA5 is closely related to the development of $\mathrm{PCa}$ (11-13). This is a strong indicator that CDCA5 may be an important protein in the development of PCa. However, the specific mechanism of action of CDCA5 in PCa development has not been reported.

The MAPK cascade signalling pathway is composed of serine and threonine kinases. This signalling pathway transfers extracellular molecules, such as hormones and tumour-promoting and differentiation molecules, into cells to regulate cell proliferation and differentiation (14). Extracellular 
signal-regulated kinase (ERK) is a member of the MAPK signalling pathway. Studies have found that aberrant Ras/ $\mathrm{Raf} / \mathrm{MEK} / \mathrm{ERK}$ activation leads to tumourigenesis (15). Increased levels of ERK phosphorylation have been revealed to be associated with poor prognosis and the progression of multiple cancers, including PCa $(16,17)$. Researchers have already revealed the relationship between CDCA5 and ERK in colorectal (10) and liver cancer (18). Based on this, we further explored whether CDCA5 exerts its function through the ERK signalling pathway in $\mathrm{PCa}$.

In the present study, the expression level of CDCA5 in PCa and the effect of CDCA5 on PCa progression via bioinformatics and molecular and cell biology assays were explored. Through existing literature support and experimental verification, it was further elucidated that CDCA5 functions through the ERK signalling pathway to promote $\mathrm{PCa}$ progression. The purpose of the present study was to confirm that CDCA5 has become a potential molecular target for PCa diagnosis and treatment.

\section{Materials and methods}

Ethical approval for the study protocol. The present study was approved by the Medical Ethics Committee of The Second Hospital of Tianjin Medical University, Tianjin, China (nos. KY2019K107 and YN2019Y99). For the collection of clinical patient samples, written informed consent was obtained from all patients. For in vivo experiments, all experiments passed the approval of the Ethics Committee of the Second Hospital of Tianjin Medical University. All studies were conducted in accordance with the Declaration of Helsinki. The Ethics approval no. KY2019K107 was used for human samples and the Ethics approval no. YN2019Y99 was used for animal experiments.

Human samples. Prostate tissue specimens were surgically removed from prostate cancer patients, with complete clinicopathological data, and cancer tissues and paracancerous tissue from each patient were collected. These patients were treated at the Second Hospital of Tianjin Medical University. The collection period was from September 2017 to February 2019. During this period, all prostate cancer patients treated in Ward B of the Department Urology of the Second Hospital of Tianjin Medical University were included in the present study. All included patients signed the informed consent form. A total of 106 patients were included, thus, a total of 106 pairs of prostate tissue and paracancerous tissue from patients were collected. Among them, 96 pairs of tissues were formalin-fixed paraffin-embedded (FFPE) for immunohistochemical (IHC) analysis, and 10 pairs of tissues were fresh tissue for reverse transcription-quantitative (RT-q)PCR. The clinicopathological data of all patients are presented in Table SI.

Antibodies. The antibodies used in the present study are listed in Table I.

Bioinformatics analysis. Gene Expression Profiling Interactive Analysis (GEPIA) (19) is an online data processing tool at http://gepia.cancer-pku.cn/index.html. The GEPIA database is based on data from the UCSC Xena project. It can analyze and process The Cancer Genome Atlas (TCGA) database (20). In the present study, GEPIA was used to determine the difference in CDCA5 mRNA between PCa tissue and normal prostate tissue in TCGA database. In addition, GEPIA was also used to explore the relationship between CDCA5 expression level and survival of PCa patients in TCGA database.

Cell culture and In vitro transfection. The cell lines RWPE-1, LNCaP, 22RV1, C4-2 and PC-3 were purchased from the ATCC. All the cell lines were cultured in RPMI-1640 medium containing 10\% foetal bovine serum (both from Gibco; Thermo Fisher Scientific, Inc.) at $37^{\circ} \mathrm{C}$ under a volume fraction of $5 \% \mathrm{CO}_{2}$. Transfection was performed using cells in the logarithmic growth phase. The cells were seeded in 6-well plates at a density of $5 \times 10^{5}$ cells/well one day prior to transfection. The following day, transfection was performed at a cell density of $60-70 \%$, and the specific procedure was carried out with Lipofectamine 3000 according to the manufacturer's instructions (Invitrogen; Thermo Fisher Scientific, Inc.). Transfection was carried out for $30 \mathrm{~min}$ at $37^{\circ} \mathrm{C}$. The following short hairpin (sh)RNA plasmids were used: CDCA5 human shRNA plasmid (cat. no. TL305489), and HuSH shRNA RFP cloning vector (cat. no. TR30014; both from OriGene Technologies, Inc.). In a 6-well plate, $2.5 \mu \mathrm{g}$ plasmid was added to each well. The time interval between transfection and subsequent experimentation was $24 \mathrm{~h}$. In the present study, the aforementioned shRNA plasmids were used to transfect PC-3 and C4-2 cell lines.

$R T-q P C R$. Total RNA from tissue was extracted using TRIzol and reverse-transcribed into cDNA using an RT kit (both Sigma-Aldrich; Merck KGaA) according to the manufacturer's instructions. TaqMan (Invitrogen; Thermo Fisher Scientific, Inc.) was used according to the manufacturer's instructions for RT-qPCR. Using the cDNA as a template, RT-qPCR was performed to detect the expression of CDCA5. Using GAPDH as an internal reference, relative quantitative analysis was performed using the $2^{-\Delta \Delta \mathrm{Cq}}$ method (21). The primer sequences were as follows: CDCA5 forward, 5'-GACGCCAGAGACTTGGAAATG-3' and reverse, 5'-GGACCTCGGTGAGTTTGGAG-3'; GAPDH forward, 5'-GATTCCACCCATGGCAAATT-3' and reverse, 5'-TCTCGCTCCTGGAAGATGGT-3'. The reaction conditions for RT-qPCR were $95^{\circ} \mathrm{C}$ for $3 \mathrm{~min}, 95^{\circ} \mathrm{C}$ for $5 \mathrm{sec}$, and $60^{\circ} \mathrm{C}$ for $30 \mathrm{sec}$. The aforementioned reaction conditions were carried out for 40 cycles, and the assays were repeated 3 times.

IHC staining. For IHC staining, 4\% paraformaldehyde was used to fix the tissue at $25^{\circ} \mathrm{C}$ for $24 \mathrm{~h}$. Paraffin was used for embedding, and the thickness of sections was $0.4 \mathrm{~mm}$. The specimen slices were routinely dewaxed with water, antigen retrieval was performed, and the sections were washed with PBS. Next, use blocking reagent to block endogenous peroxidase activity, and the sections were washed again with PBS. Primary antibodies were added dropwise and incubated at $4^{\circ} \mathrm{C}$ for $18 \mathrm{~h}$. The sections were washed again with PBS, and secondary antibodies (general purpose secondary antibody; dilution 1:10; PV-6000; ZSGB-BIO; OriGene Technologies, Inc.) were added dropwise and incubated at $37^{\circ} \mathrm{C}$ for $1 \mathrm{~h}$. The sections were washed again with PBS; then, DAB colouring solution was added dropwise for colour development, and the 
Table I. Antibodies used in the present study.

\begin{tabular}{lll}
\hline ID & \multicolumn{1}{c}{ Product code or cat. no., supplier } & \multicolumn{1}{c}{ Instructions } \\
\hline CDCA5 & ab192237, Abcam & $1: 1,000$ dilution for western blotting \\
Ki67 & ab16667, Abcam & $1: 100$ dilution for IHC \\
& & $1: 1,000$ dilution for western blotting \\
Cleaved caspase-3 & ab2302, Abcam & $1: 200$ dilution for IHC \\
& & $1: 500$ dilution for western blotting \\
Pro caspase-3 & ab32150, Abcam & $1: 100$ dilution for IHC \\
& & $1: 1,000$ dilution for western blotting \\
ERK & ab54230, Abcam, & $1: 200$ dilution for IHC \\
p-ERK & & $1: 2,000$ dilution for western blotting \\
& & $1: 100$ dilution for IHC \\
CDK1 & ab50011, Abcam & $1: 1,000$ dilution for western blotting \\
Cyclin B1 & & $1: 100$ dilution for IHC \\
GAPDH & ab131450, Abcam & $1: 100$ dilution for western blotting \\
\end{tabular}

CDCA5, cell division cycle-associated 5; ERK, extracellular signal-regulated kinase; p-, phosphorylated; IHC, immunohistochemistry.

colour development was immediately stopped. After washing with tap water, the nuclei were counterstained with haematoxylin $\left(25^{\circ} \mathrm{C}, 15 \mathrm{sec}\right)$. Finally, the samples were dehydrated, cleared, sealed and observed under a light microscope.

Western blotting. Protein lysis buffer (Thermo Fisher Scientific, Inc.) was used to extract total cell protein. After using the bicinchoninic acid (BCA) method to determine the protein concentration, loading buffer was used to prepare the protein samples (30 $\mu \mathrm{g}$ per lane) for SDS-PAGE (the percentage of the gel was $10 \%$ ) electrophoresis. After electrophoresis, the protein was transferred to a PVDF (Thermo Fisher Scientific, Inc.) membrane at a constant flow rate of $250 \mathrm{~mA}$ for $130 \mathrm{~min}$. Next, the membrane was sealed with $5 \%$ skimmed milk at room temperature for $1 \mathrm{~h}$. Then, the membrane was washed with TBST solution, the PVDF membrane was incubated with primary antibody and incubated overnight at $4^{\circ} \mathrm{C}$. Subsequently, the membrane was washed 3 times with TBST for 5 min each time. Then, secondary antibodies [(mouse IgG $(\mathrm{H}+\mathrm{L})$ cross-adsorbed secondary antibody; cat. no. G-21040; 1:10,000 dilution); or (rabbit $\mathrm{IgG}(\mathrm{H}+\mathrm{L})$ secondary antibody cat. no. 31460, 1:10,000 dilution); both from Thermo Fisher Scientific, Inc.] was added and incubated for $1 \mathrm{~h}$ at room temperature. The PVDF membrane was washed 3 times with TBST again for $5 \mathrm{~min}$ each time. Finally, a visualisation reagent $\left(\right.$ Pierce ${ }^{\mathrm{TM}}$ ECL Western Blotting Substrate; Thermo Fisher Scientific, Inc.) was dropped on the PVDF membrane for exposure.

Flow cytometry. Culture growth was terminated when the total number of cells reached $1 \times 10^{6}$. The cells were digested with trypsin, centrifuged at $157 \times \mathrm{g}$ at $4^{\circ} \mathrm{C}$ for $3 \mathrm{~min}$, and the supernatant was discarded. The cells were fixed with $70 \%$ icecold alcohol and allowed to stand at $4^{\circ} \mathrm{C}$ overnight. The cells were washed twice with ice-cold PBS, centrifuged at $157 \mathrm{x} \mathrm{g}$ at $4^{\circ} \mathrm{C}$ for $3 \mathrm{~min}$, stained with a fluorescent solution (PE Annexin V Apoptosis; cat. no. 559763; BD Pharmingen ${ }^{\mathrm{TM}}$; BD Biosciences) at $25^{\circ} \mathrm{C}$ for $3 \mathrm{~min}$, and then gently mixed. After incubation for $30 \mathrm{~min}$ at room temperature, the cells were analyzed and mapped using flow cytometer (Cytomics FC 500 MCL; Beckman Coulter, Inc.).

MTT assay. Cells were seeded on 96-well plates at 2,000 cells per well, each well contained $150 \mu 1$ of culture medium, and the cells were cultured in a conventional cell culture method for 6 days. Then, $20 \mu \mathrm{l}$ of MTT (Sigma-Aldrich; Merck KGaA) solution was added to each well. After incubation at $37^{\circ} \mathrm{C}$ for $4 \mathrm{~h}$, the culture supernatant in the wells was discarded. Then, $150 \mu \mathrm{l}$ of DMSO (Sigma-Aldrich; Merck KGaA) was added to each well and shaken for 10 min to allow the crystals to fully dissolve. A microplate reader (FC; Thermo Fisher Scientific, Inc.) was used for detection. The light absorption value at $570 \mathrm{~nm}$ was detected, and the cell growth curve was plotted with time as the abscissa and absorbance as the ordinate.

Colony formation assay. Cells in the logarithmic growth phase were collected, and $1 \times 10^{3}$ cells/well were seeded in a 6 -well plate. Three replicate wells were used for each group. When macroscopic colonies appeared after 7 days of culture, the culture solution was discarded. After washing with PBS, the cells were fixed in a $4 \%$ methanol solution at $25^{\circ} \mathrm{C}$ for $15 \mathrm{~min}$ and stained with $10 \%$ haematoxylin at $25^{\circ} \mathrm{C}$ for $15 \mathrm{~min}$. The cells were then observed under an optical microscope (magnification $\mathrm{x} 40$ ), and the number of colonies was counted. The minimum number of cells per colony was 50 .

Transwell invasion assay. Matrigel (BD Biosciences) was melted at $4^{\circ} \mathrm{C}$ overnight. On ice, a pre-cooled pipette tip was used to draw $100 \mu \mathrm{l}$ Matrigel into the pre-cooled $300 \mu \mathrm{l}$ serum-free medium and was well mixed. Then, $25 \mu \mathrm{l}$ of the 


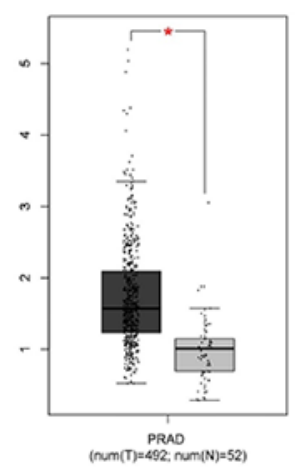

B

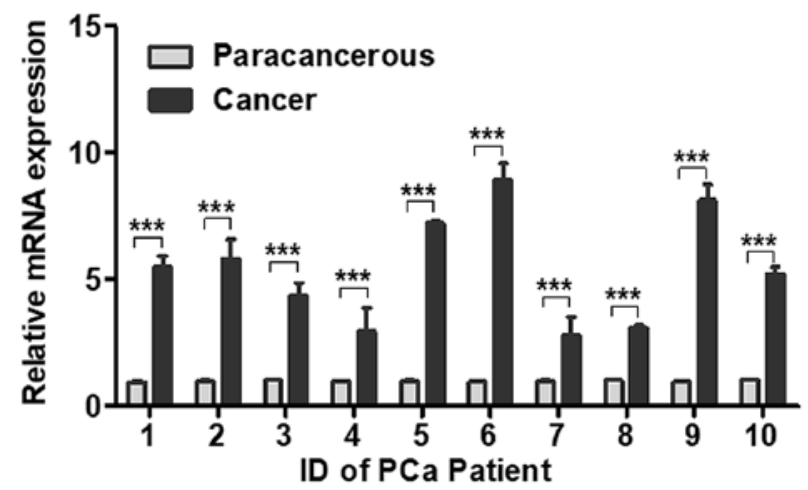

c

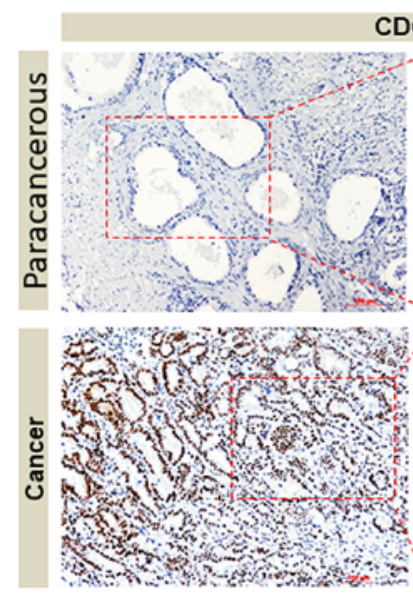

D

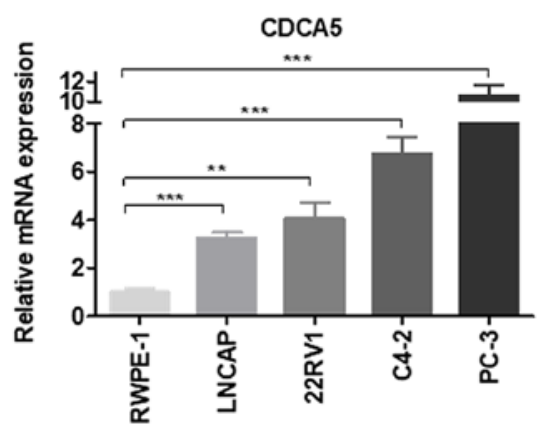

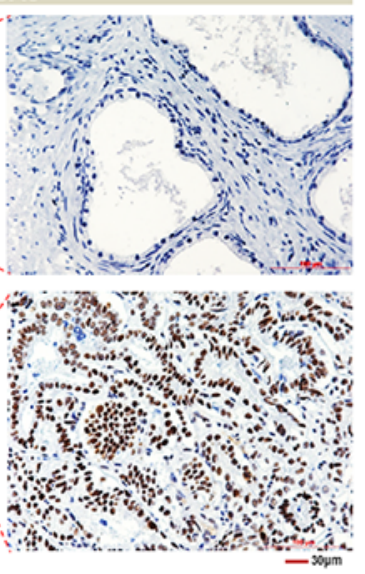

E
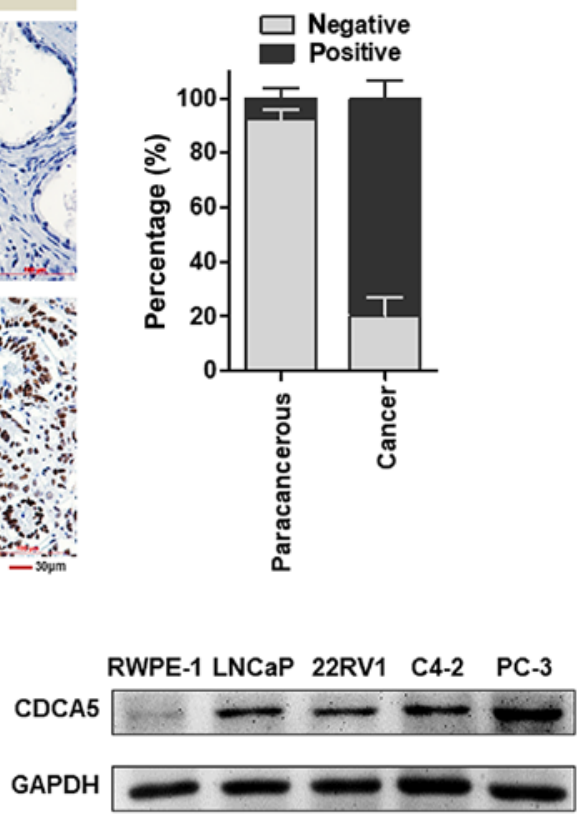

Figure 1. CDCA5 expression is higher in PCa tissues than in adjacent tissues. (A) GEPIA was used to assess the differences in CDCA5 mRNA levels in PCa tissues and normal prostate tissues in TCGA database $\left[\left(\operatorname{num}(\mathrm{T})=492, \operatorname{num}(\mathrm{N})=52,{ }^{*} \mathrm{P}<0.05\right]\right.$. (B) RT-qPCR was used to detect the CDCA5 mRNA expression level in PCa and adjacent surgical specimens from tumour patients ( $\mathrm{n}=10$ pairs $)\left({ }^{* * * *} \mathrm{P}<0.001\right)$. (C) Representative IHC images of CDCA5 in PCa and paracancerous tissues (magnification, $\mathrm{x} 200$ and $\times 400$ ). The histogram revealed the statistical results of the histochemical positive rate (right panel) (n=96). (D) RT-qPCR was used to detect the mRNA expression levels of CDCA5 in RWPE-1, LNCaP, 22RV1, C4-2 and PC-3 cells. GAPDH was used as an internal control $\left(\mathrm{n}=3 ;{ }^{* *} \mathrm{P}<0.01\right.$ and $\left.{ }^{* * *} \mathrm{P}<0.001\right)$. (E) Western blotting was used to detect the protein expression levels of CDCA5 in RWPE-1, LNCaP, 22RV1, C4-2 and PC-3 cells. GAPDH was used as an internal control. CDCA5, cell division cycle-associated 5; PCa, prostate cancer; GEPIA, Gene Expression Profiling Interactive Analysis; TCGA, The Cancer Genome Atlas; RT-qPCR, reverse transcription-quantitative PCR.

aforementioned-diluted Matrigel was obtained and added to a Transwell plate chamber (BD FALCON; product no. 353097; pore size of the inserts, $8 \mu \mathrm{m}$; Corning, Inc.), and placed at $37^{\circ} \mathrm{C}$ for $30 \mathrm{~min}$ to polymerize the Matrigel into a gel. A single cell suspension was prepared with a serum-free medium using a conventional method (22), and the concentration of the cell suspension was $5 \times 10^{5}$ cells $/ \mathrm{ml}$. Then, $100 \mu \mathrm{l}$ of cell suspension was added to the chamber of the Transwell culture plate and $200 \mu 1$ of serum-free medium. Subsequently, $500 \mu 1$ of medium containing 10\% FBS was added to the lower chamber of the Transwell culture plate, and cultured in RPMI-1640 medium containing 10\% fetal bovine serum (both from Gibco; Thermo Fisher Scientific, Inc.) at $37^{\circ} \mathrm{C}$ under a volume fraction of
$5 \% \mathrm{CO}_{2}$. The Matrigel gel and the cells on the upper surface of the Transwell culture plate were then wiped off. The cells were fixed with $10 \%$ methanol at $25^{\circ} \mathrm{C}$ for $30 \mathrm{~min}$. Crystal violet dye at a concentration of $0.1 \%$ was used to stain the cells at $37^{\circ} \mathrm{C}$ for $1 \mathrm{~min}$. The excess crystal violet dye was rinsed with PBS, and the cells were observed and counted under a light microscope (magnification, $\mathrm{x} 200$ ).

Cell cycle analysis. The cells $\left(1 \times 10^{6} / \mathrm{ml}\right)$ to be assessed were fixed with $70 \%$ ethanol at $4^{\circ} \mathrm{C}$ for $8 \mathrm{~h}$, and stained with propidium iodide (PI; $0.5 \mathrm{mg} / \mathrm{ml}$; Thermo Fisher Scientific, Inc.) at $37^{\circ} \mathrm{C}$ for $30 \mathrm{~min}$. A FACSCaliber flow cytometer (BD Biosciences) was used to analyse the number of cells in 
Table II. Clinicopathologic variables and CDCA5 expression in PCa patients $(n=96)$.

\begin{tabular}{|c|c|c|c|c|c|}
\hline \multirow[b]{2}{*}{ Variables } & \multirow[b]{2}{*}{ Group } & \multicolumn{3}{|c|}{ CDCA5 expression } & \multirow[b]{2}{*}{ P-value ${ }^{a}$} \\
\hline & & $\mathrm{n}=96$ & High & Low & \\
\hline Age (years) & $\begin{array}{l}<65 \\
\geq 65\end{array}$ & $\begin{array}{l}46 \\
50\end{array}$ & $\begin{array}{l}32 \\
32\end{array}$ & $\begin{array}{l}14 \\
18\end{array}$ & 0.56 \\
\hline Preoperative PSA & $\begin{array}{l}\leq 10 \\
>10\end{array}$ & $\begin{array}{l}25 \\
71\end{array}$ & $\begin{array}{l}12 \\
52\end{array}$ & $\begin{array}{l}13 \\
19\end{array}$ & $0.02^{\mathrm{b}}$ \\
\hline Clinical stage & $\begin{array}{c}\mathrm{T} 1 \\
\mathrm{~T} 2-3\end{array}$ & $\begin{array}{l}30 \\
66\end{array}$ & $\begin{array}{l}16 \\
48\end{array}$ & $\begin{array}{l}14 \\
18\end{array}$ & 0.06 \\
\hline Gleason score & $\begin{array}{l}<7 \\
\geq 7\end{array}$ & $\begin{array}{l}35 \\
61\end{array}$ & $\begin{array}{l}20 \\
44\end{array}$ & $\begin{array}{l}15 \\
17\end{array}$ & 0.13 \\
\hline Seminal vesicle invasion & $\begin{array}{l}\text { Absence } \\
\text { Presence }\end{array}$ & $\begin{array}{l}36 \\
60\end{array}$ & $\begin{array}{l}19 \\
45\end{array}$ & $\begin{array}{l}17 \\
15\end{array}$ & $0.03^{\mathrm{b}}$ \\
\hline Lymph node metastasis & $\begin{array}{l}\text { Absence } \\
\text { Presence }\end{array}$ & $\begin{array}{l}40 \\
56\end{array}$ & $\begin{array}{l}22 \\
42\end{array}$ & $\begin{array}{l}18 \\
14\end{array}$ & $0.04^{\mathrm{b}}$ \\
\hline
\end{tabular}

${ }^{\text {aP }} \mathrm{P}$-value was analyzed by Chi-square test; ${ }^{\mathrm{b}} \mathrm{P}<0.05$ indicates statistical significance. CDCA5, cell division cycle-associated 5 ; $\mathrm{PCa}$, prostate cancer.

different cell-cycle stages and calculate the corresponding percentages.

In vivo experiments. The animal studies were approved by The Second Hospital of Tianjin Medical University, Tianjin, China. Male nude mice ( 6 weeks old; $n=6 ; 16-20$ g per mouse) were purchased from Beijing HFK Bioscience Co., Ltd. There were no more than 5 mice in each cage. The temperature in the cage was maintained at $26-28^{\circ} \mathrm{C}$, and the relative humidity at 40-60\%. A high-efficiency filter was used to ensure that constant ventilation. The experimental mice were fed with sterilized feed and water ad libitum. Subcutaneous tumour growth assays were performed with shCON-PC-3 and shCDCA5-PC-3 stable cell lines (1x10 6 shCON-PC-3 cells were injected into 3 mice and $1 \times 10^{6}$ shCDCA5-PC-3 cells were injected into the other 3 mice). After two weeks, the 6 injected mice developed tumours. The tumour size was measured every 7 days with a Vernier calliper, and the volume change of the tumour was calculated. When the length of the largest tumour among all tumours reached $20 \mathrm{~mm}$, the experiment required termination to avoid tumor rupture. The experimental mice were euthanized by inhaling excessive $\mathrm{CO}_{2}$. The air displacement rate of $\mathrm{CO}_{2}$ in $\% / \mathrm{min}$ was $15 \% / \mathrm{min}$. Animal experiments were performed from September 5, 2019 to November 17, 2019. The tumours were harvested under standard, institutionally approved processes. The mass of each tumour was measured with an electronic balance. Tumour samples were paraffin-fixed and processed for IHC analysis.

Statistical analysis. Statistical analysis was performed using SPSS 20.0 statistical software (IBM Corp.). Each experiment in the present study was repeated independently 3 times. All results are expressed as the mean \pm standard deviation (SD). Comparisons between groups were performed using one-way analysis of variance (ANOVA). CDCA5 mRNA expression levels in different cell lines were compared using ANOVA followed by Dunnett's post hoc test. An independent sample unpaired Student's t-test was used for direct comparisons between two groups. Pearson $\chi^{2}$ test was used to analyse the relationship between CDCA5 protein expression level and clinicopathological characteristics. Differences were considered statistically significant at $\mathrm{P}<0.05$.

\section{Results}

CDCA5 expression is higher in PCa tissues than in normal prostate tissues. In the present study, GEPIA was used to determine the difference in CDCA5 mRNA between PCa tissue and normal prostate tissue in TCGA database. The results revealed that the mRNA level of CDCA5 was significantly increased in $\mathrm{PCa}$ tissues $(\mathrm{P}<0.05$, num $(\mathrm{T})=492$; $\operatorname{num}(\mathrm{N})=52$; Fig. $1 \mathrm{~A})$. To verify the aforementioned results, $\mathrm{PCa}$ tissues and prostate paracancerous tissues were collected concurrently from 10 patients with tumours at the Second Hospital of Tianjin Medical University. Total RNA was extracted from the tissues, and the CDCA5 mRNA expression level was examined. The RT-qPCR results revealed that CDCA5 mRNA expression was significantly higher in the 10 pairs of $\mathrm{PCa}$ tissues than in paracancerous tissues (Fig. 1B). To further explore the protein expression of CDCA5 in PCa tissues, relevant paraffin sections were obtained from the Second Hospital of Tianjin Medical University. The pathologists confirmed that the normal prostate tissue acinus was small and round, the basal cells were flat and in a continuous line at the base of the gland, and the nucleus was arranged neatly. IHC results revealed that the protein level of CDCA5 was significantly higher in $\mathrm{PCa}$ tissues than in paracancerous tissues (Fig. 1C) $(\mathrm{n}=96)$. In vitro, it was confirmed that CDCA5 mRNA and protein expression levels were higher in several PCa cell lines (LNCAP, 22RV1, 
A

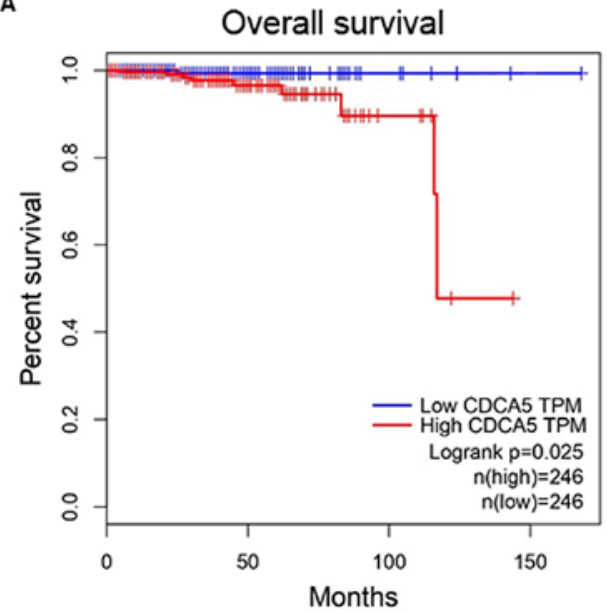

B

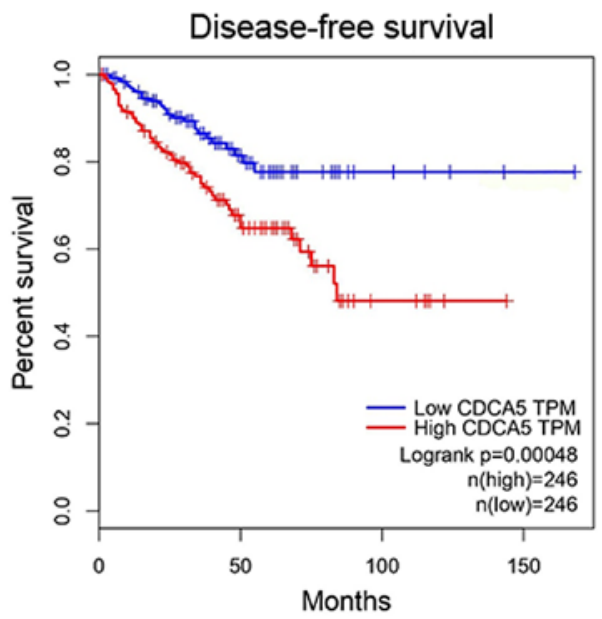

Figure 2. Relationship between CDCA5 expression and patient survival. GEPIA was used to map the (A) overall survival ( $\mathrm{n}=492$, $\mathrm{P}=0.025)$ and (B) diseasefree survival ( $\mathrm{n}=492, \mathrm{P}=0.00048)$ curves for patients with PCa. CDCA5, cell division cycle-associated 5; PCa, prostate cancer; GEPIA, Gene Expression Profiling Interactive Analysis.

C4-2 and PC-3) than in human normal prostate epithelial cells (RWPE-1) (Fig. 1D and E).

CDCA5 expression affects the prognosis of $\mathrm{PCa}$ patients. The CDCA5 staining and clinicopathological features of the aforementioned clinical specimens were comprehensively analysed. Table II revealed that patients with high CDCA5 expression had a high initial PSA. Additionally, seminal vesicle invasion and lymph node metastasis were more likely to occur.

GEPIA was used to explore the relationship between CDCA5 expression level and survival in PCa patients. All the relevant data were obtained from TCGA database. CDCA5 mRNA expression was classified as low $(n=246)$ or high $(n=246)$ based on the median CDCA5 mRNA expression level as a cut-off point. The analysis results revealed that both the overall survival $(\mathrm{P}=0.025)$ and disease-free survival $(\mathrm{P}=0.00048)$ were significantly different between the high and low CDCA5 expression groups (Fig. 2A and B). Thus, it could be inferred that the expression of CDCA5 may be used as a predictor of prognosis in $\mathrm{PCa}$ patients.

CDCA5 knockdown inhibits PCa cell proliferation and invasion in vitro. In vitro experiments further explored the effect of CDCA5 on PCa cell function. The protein expression levels of CDCA5 were examined in the PCa cell lines LNCaP, 22RV1, C4-2 and PC-3. Among them, the CDCA5 protein expression level was the highest in $\mathrm{C} 4-2$ and $\mathrm{PC}-3$ cells (Fig. 1E). Therefore, C4-2 and PC-3 cells were selected for our experimental research. Next, two stable cell lines with CDCA5 knockdown were established. Through proliferationrelated functional protein markers, it was determined that when CDCA5 was knocked down, Ki67 expression levels decreased in C4-2 and PC-3 cells and cleaved caspase-3 expression was increased (Fig. 3A). Moreover, flow cytometric results revealed that the apoptotic rate (early apoptosis + late apoptosis) of shCDCA5-C4-2 and shCDCA5-PC-3 cells was significantly higher than the rate of apoptotic C4-2 and PC-3 control cells respectively (Fig. 3B). An MTT assay revealed that the proliferative capacity of C4-2 and PC-3 cells was signifi- cantly decreased after CDCA5 was knocked down (Fig. 3C). Moreover, colony formation assays revealed that the cloning ability of C4-2 and PC-3 cells was significantly decreased after CDCA5 was knocked down (Fig. 3D). The statistical results for the number of colonies revealed significant differences between the two groups (Fig. 3E). The experimental results revealed that when the CDCA5 of prostate cancer cells PC-3 or C4-2 was knocked down, their invasion ability was significantly reduced (Fig. 3F). The statistical results for the number of colonies revealed significant differences between the two groups (Fig. 3G). These data indicated that after knocking down CDCA5, the proliferation and invasion abilities of $\mathrm{PCa}$ cells were decreased.

CDCA5 regulates the prostate cancer cell division cycle. The proliferation of eukaryotic cells is mainly mediated by the cell cycle. The $\mathrm{G} 2 / \mathrm{M}$ process is one of the main checkpoints and is tightly regulated by the cyclin B1/CDK1 protein complex (10). CDCA5 is required for the stable binding of adhesion and chromatin in the G2/M phase and plays a vital role in cell cycle regulation. Researchers have found that CDCA5 can affect the cell division cycle in several tumours (23). Thus, the effects CDCA5 on the prostate cancer cell division cycle were explored. Cell cycle analysis revealed a decreased percentage of $\mathrm{G} 0 / \mathrm{G} 1$ phase cells and an increased percentage of $\mathrm{G} 2 / \mathrm{M}$ phase cells for both the C4-2 and PC-3 cell lines (Fig. 4A and B). These phenomena indicated that after CDCA5 knockdown in PC-3 and C4-2 cells, the G2/M process was blocked. The expression of the G2/M-related proteins CDK1 and cyclin B1 was decreased by CDCA5 knockdown in C4-2 and PC-3 cells (Fig. 4C and D).

CDCA5 knockdown inhibits ERK signalling pathway activation. Researchers have reported that activation of the ERK signalling pathway plays a key role in PCa development, and activation of this pathway is dependent on ERK phosphorylation (24). We also obtained similar conclusions in our experiment. The phosphorylation level of ERK in C4-2 and PC-3 cells was significantly decreased after knocking down 
A
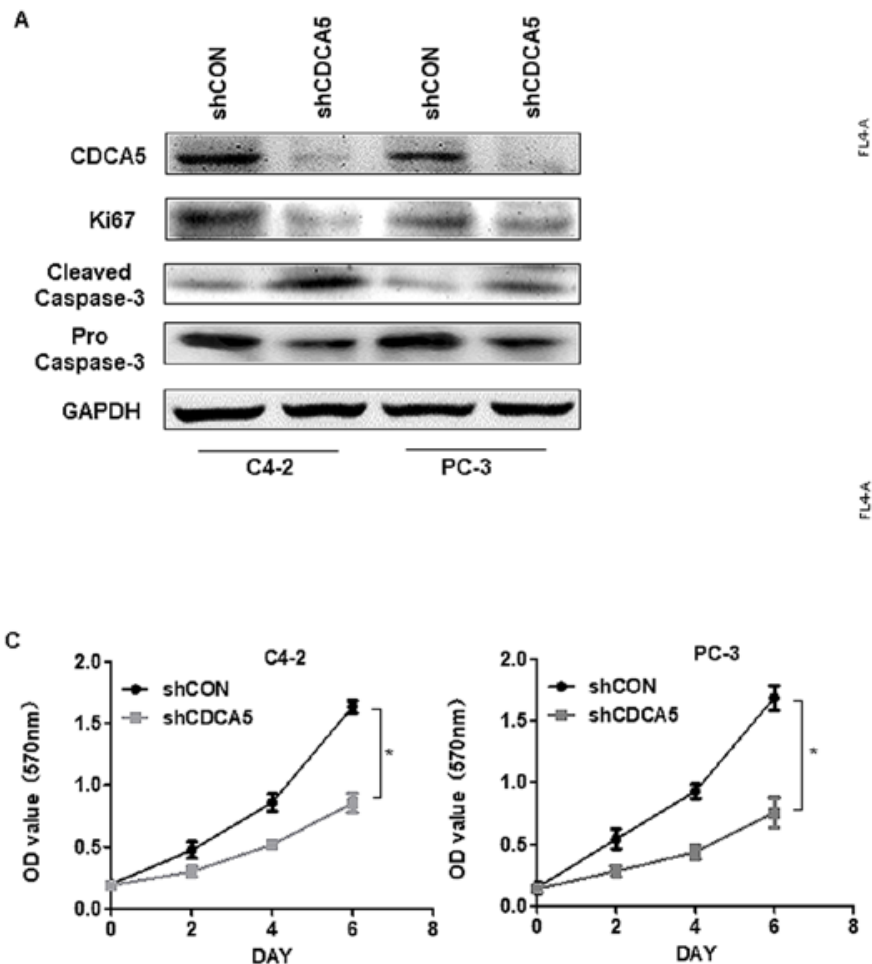

B
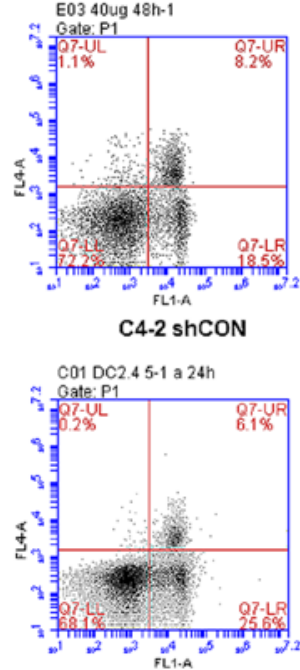

$\mathrm{PC}-3$ shCON

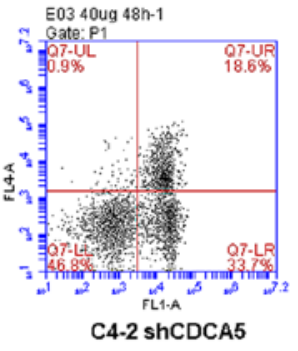

C01 DC2.45-1 a 24h

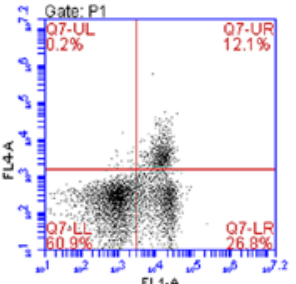

PC-3 shCDCA5

D

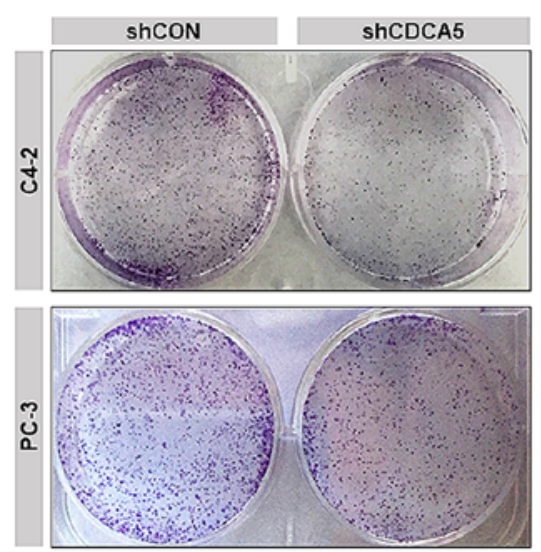

F

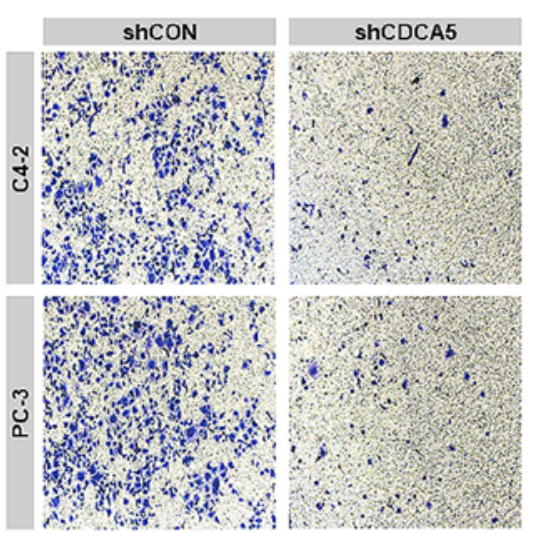

E

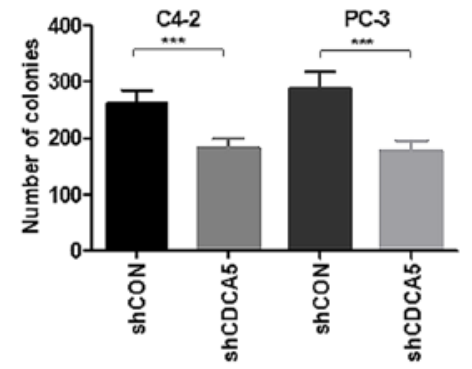

G

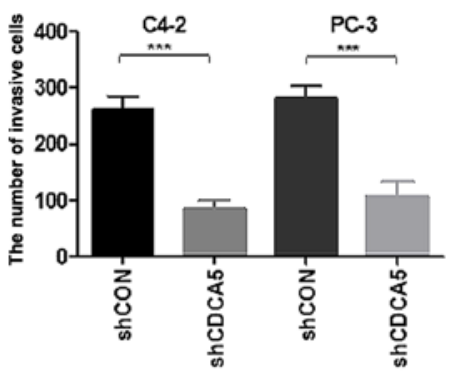

Figure 3. Knockdown of CDCA5 inhibits PCa cell proliferation and invasion in vitro. (A) Western blotting was used to detect the expression levels of CDCA5, Ki67 and cleaved/pro caspase-3 after CDCA5 knockdown in C4-2 and PC-3 cells. GAPDH was used as an internal control. (B) Flow cytometry was used to detect apoptosis in C4-2 and PC-3 cells after CDCA5 knockdown. The apoptotic rate (early apoptosis + late apoptosis) of C4-2 and PC-3 after knockdown CDCA5 was counted and plotted on a graph $\left({ }^{* *} \mathrm{P}<0.01\right.$ and $\left.{ }^{* * * *} \mathrm{P}<0.001\right)$. The UL region indicates cell necrosis, the LL region indicates cell survival, the LR region indicates early cell apoptosis, and the UR region indicates late cell apoptosis. The LR region + UR region indicate total apoptosis. (C) An MTT assay was used to detect C4-2 and PC-3 cell growth after CDCA5 was knocked down. The absorbance value at a wavelength of $570 \mathrm{~nm}$ was detected ("P<0.05). (D) A colony formation assay was used to detect C4-2 and PC-3 cell growth after CDCA5 knockdown. (E) The number of colonies from D was counted and plotted $\left.{ }^{(* * * *} \mathrm{P}<0.001\right)$. (F) Transwell invasion assays detected the invasiveness of the prostate cancer cells after knockdown of CDCA5. (G) The number of invaded cells in F was counted and plotted on a graph $\left.{ }^{(* * *} \mathrm{P}<0.001\right)$. CDCA5, cell division cycle-associated 5; PCa, prostate cancer; sh, short hairpin; CON, control; UL, upper left; LL, lower left; LR, lower right; UR, upper right. 

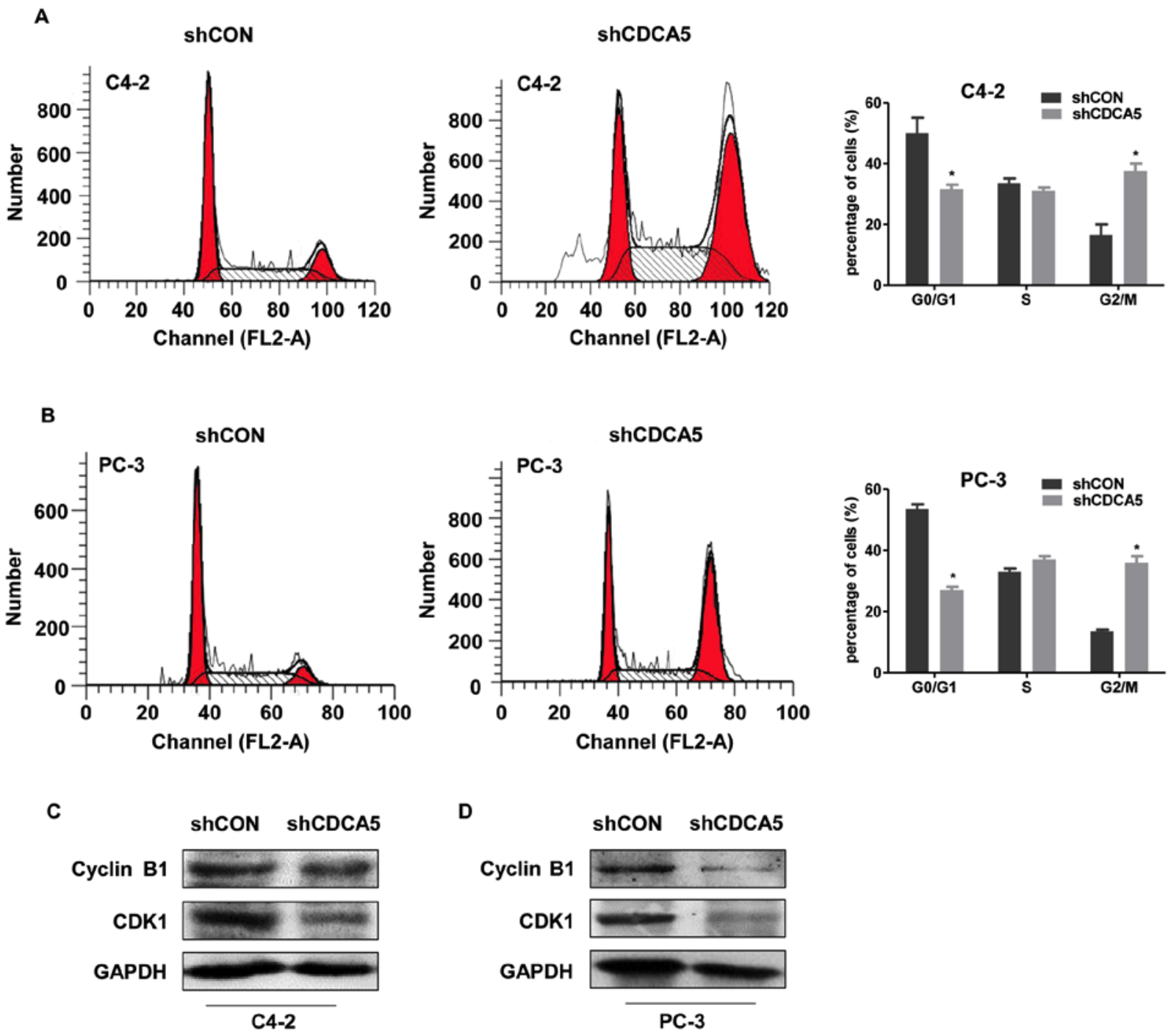

Figure 4. CDCA5 knockdown induces cell cycle arrest. (A and B) Cell cycle distribution was determined by flow cytometric analysis in (A) C4-2 and (B) PC-3 cells after CDCA5 knockdown. The percentages of cells in the G0/G1, S and G2/M phases were calculated ("P $<0.05$ ). (C and D) Western blotting was used to detect the expression levels of cyclin B1 and CDK1 after CDCA5 knockdown in C4-2 and PC-3 cells. GAPDH was used as an internal control. CDCA5, cell division cycle-associated 5; sh, short hairpin; $\mathrm{CON}$, control.

CDCA5 (Fig. 5A and B). IHC analysis of the 96 clinical specimens aforementioned (CDCA5-low, $n=32$; CDCA5high, $n=64$ ) was conducted. Notably, it was revealed that PCa patients with high levels of CDCA5 also had high ERK phosphorylation levels and Ki67 expression levels (Fig. 5C). In contrast, the expression level of caspase- 3 in prostate cancer patients with high expression of CDCA5 was low (Fig. 5C). This revealed that highly expressed CDCA5 could promote the proliferation of prostate cancer cells and inhibit their apoptosis. In summary, it was inferred that CDCA5 may participate in the activation of the ERK signalling pathway in prostate cancer.

Knockdown of CDCA5 suppresses prostate tumour growth in vivo. To investigate the effect of CDCA5 expression on prostate tumour growth, a mouse xenograft model was established. Because the expression of CDCA5 protein in the PC- 3 cell line was higher than that of C4-2 (Fig. 1E), PC-3 was selected for in vivo experiments. Another reason for this selection was that PC-3 cells were more capable of forming tumours in vivo.
The six nude mice were equally divided into two groups and were injected with shCON-PC-3 and shCDCA5-PC-3 cells subcutaneously. Tumour formation was visible to the naked eye in the nude mice two weeks later. Starting from the second week, the sizes of the tumours were measured once a week and the tumour growth curve was plotted. The tumours were removed at the fifth week (Fig. 6A), and the weight of the tumour was measured. It was revealed that the tumour growth rate and weight were greater in the shCON-PC-3 group than in the shCDCA5-PC-3 group (Fig. 6B and C). This indicated that the growth of PC-3 cells was inhibited after knocking down CDCA5 in vivo. Immunohistochemical staining on the tumours was performed, and the results revealed that CDCA5 knockdown significantly decreased the phosphorylation of ERK (Fig. 6D). Similar to previous results, when CDCA5 was knocked down, the Ki67 expression level decreased, and the cleaved caspase-3 level was increased in the tumours (Fig. 6D). Proteins were extracted from the aforementioned tumours and the relevant protein markers were detected by western blotting. The experimental results obtained were consistent with the 
A

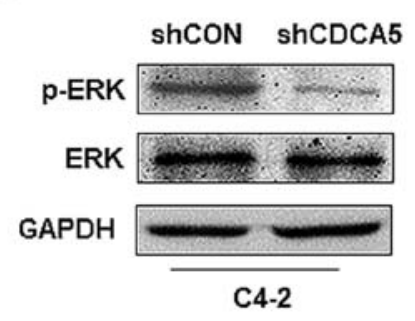

B

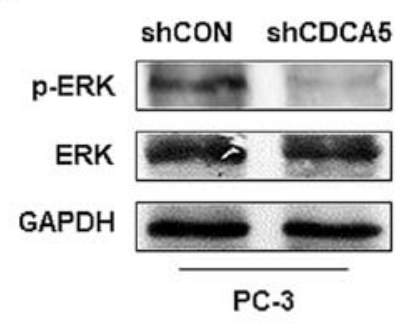

C
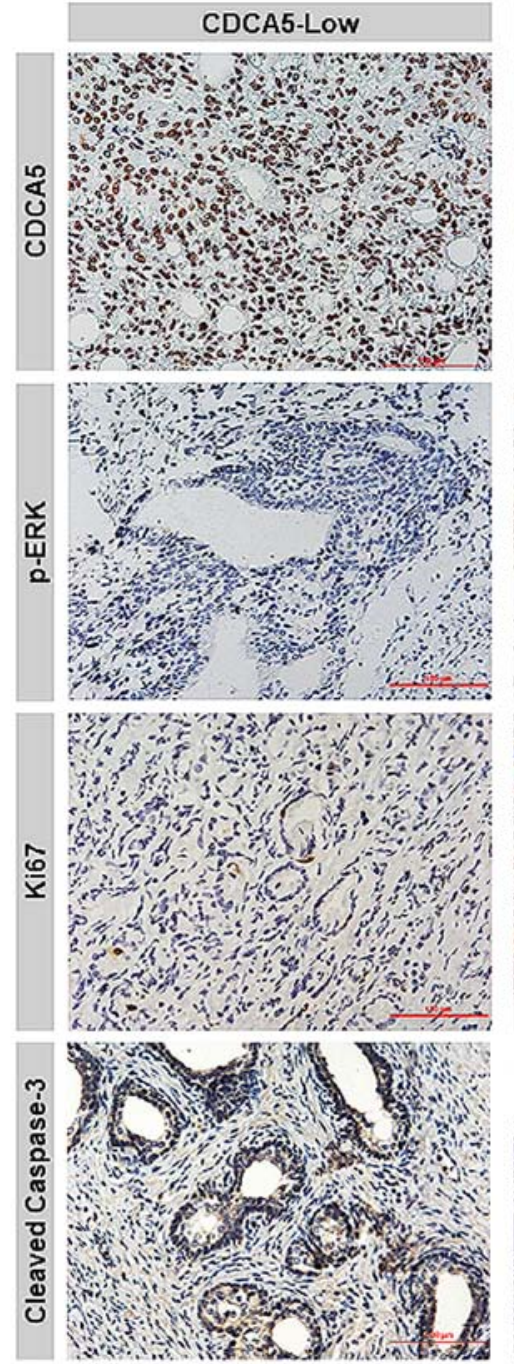
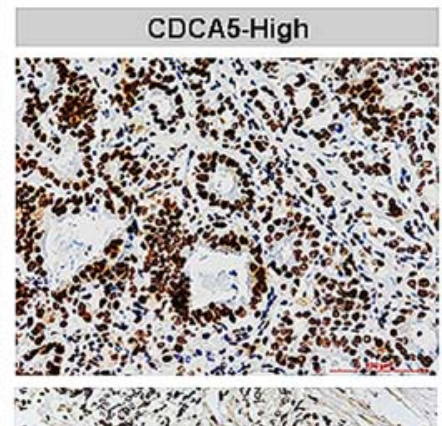

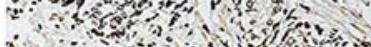
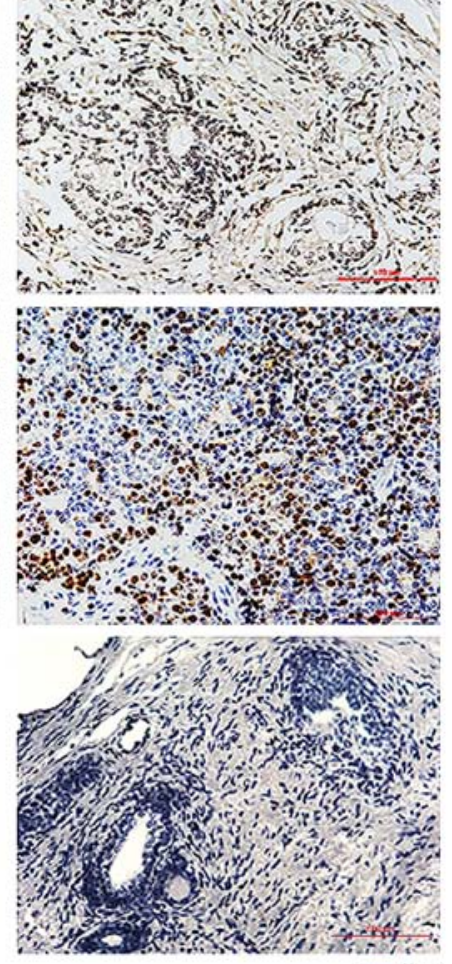

Figure 5. CDCA5 knockdown inhibits ERK signalling pathway activation. (A and B) Western blotting was used to detect the total ERK protein expression levels and ERK phosphorylation levels after CDCA5 knockdown in C4-2 and PC-3 cells. GAPDH was used as an internal control. (C) Representative pictures of the protein expression levels of CDCA5, p-ERK, Ki67 and cleaved caspase-3 in patient specimens. The magnification of the images are $\mathrm{x} 200$ ( $\mathrm{n}=96$ ). CDCA5, cell division cycle-associated 5; ERK, extracellular signal-regulated kinase; sh, short hairpin; CON, control; p-, phosphorylated.

IHC results (Fig. 6E). Thus, after knocking down CDCA5, the proliferation ability of PCa cells was decreased, and apoptosis was more likely to occur.

\section{Discussion}

Malfunctions in cell division can lead to cancer (25). Disturbance of cell cycle regulation is an important biological feature of malignant tumours and can lead to reduced apoptosis, unlimited proliferation, and metastasis in malignant cells. Cell cycle disruption is one of the most important causes of malignant tumours (26). Numerous cell cycle-related genes are dysregulated in cancer, and these genes may be potential targets for drug therapy $(27,28)$. CDCA5 belongs to a family of cell division cycle-associated proteins whose primary role is to promote sister chromatid binding and to ensure accurate sister chromatid segregation to maintain genomic integrity (3). CDCA5 regulates the activity of cell cycle-associated proteins and transcription factors, promotes the proliferation of cancer cells, and participates in the apoptosis of cancer cells (5).
Researchers have revealed that CDCA5 was highly expressed in endometrial cancer tissues (12), consistent with the findings of high CDCA5 expression in liver (8) and gastric cancer (29) tissues. Nguyen et al also revealed that CDCA5 was upregulated in lung cancer tissues (7), and poor prognosis in non-small cell lung cancer patients was associated with CDCA5 overexpression. In a study of urothelial carcinoma, CDCA5 was revealed to play a crucial role in DNA repair, and CDCA5 overexpression was a predictor of poor prognosis (6). After searching the current literature, it was revealed that there is little research on the correlation between CDCA5 and prostate cancer pathogenesis. In the present study, the upregulation of CDCA5 expression in prostate cancer was confirmed using both clinical data and cell lines. The results of the chi-square test indicated that high CDCA5 expression was positively associated with the malignant degree of prostate cancer.

CDCA5 is required for $\mathrm{G} 2 / \mathrm{M}$ phase chromatid condensation and stable binding and plays an important role in cell cycle regulation (30-32). G2/M progression, as one of the main checkpoints of the cell division cycle, is regulated by 
A

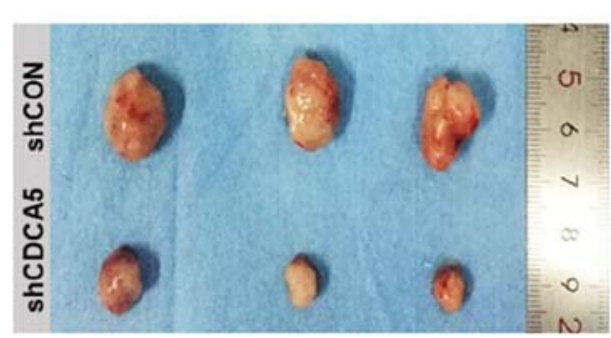

B

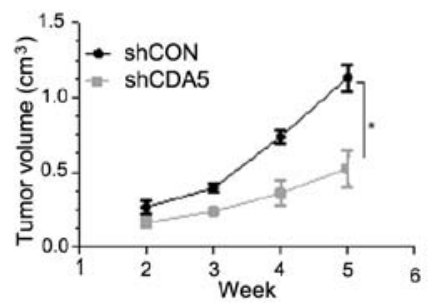

C

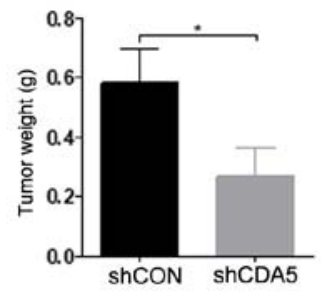

D
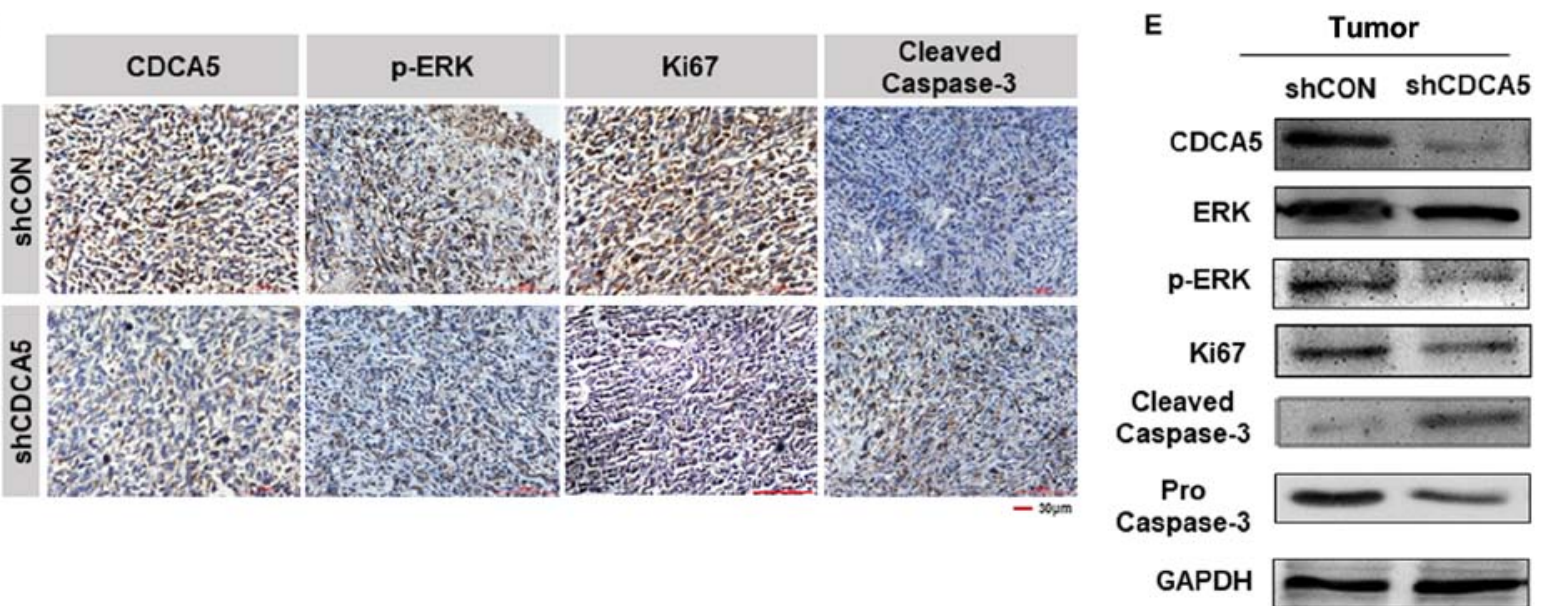

Figure 6. CDCA5 knockdown inhibits prostate tumour growth in vivo. (A and B) Volumes of PC-3 subcutaneous xenograft tumours were compared between the shCDCA5 and shCON groups $\left(n=6,{ }^{*} \mathrm{P}<0.05\right)$. (C) Tumour weights were compared between the shCDCA5 and shCON groups $\left(\mathrm{n}=6,{ }^{*} \mathrm{P}<0.05\right)$. (D) Representative images of the protein expression levels of CDCA5, p-ERK, Ki67 and cleaved caspase-3 in xenograft tumours ( $\mathrm{n}=6$ ). (E) Western blot analysis of CDCA5, ERK, p-ERK, Ki67 and cleaved/pro caspase-3 expression levels in the tumours from the shCDCA5 and shCON groups. GAPDH was used as an internal control. CDCA5, cell division cycle-associated 5; sh, short hairpin; CON, control; p-, phosphorylated; ERK, extracellular signal-regulated kinase.

the protein complex of cyclin B1/CDK1 $(9,10,33)$. It has been reported that inhibiting the expression of the CDCA5 gene can affect the cell division cycle of liver cancer cells and colorectal cancer cells, resulting in a decrease in viability $(10,18)$. shRNA was used to knock down CDCA5 in PCa cells and it was determined that their proliferative capacity was significantly reduced, and $\mathrm{G} 2 / \mathrm{M}$ progression in the cell cycle was effectively blocked. These results are consistent with previous research results $(9,10)$.

The association of CDCA5 with tumour-associated signalling pathways was further explored. It has been revealed that ERK acts as a protein-regulating kinase involved in the regulation of a variety of cellular processes, including proliferation, differentiation, inflammation, transcriptional regulation and development (34-38). Activation of the ERK signalling pathway has been revealed to be closely associated with the development of multiple tumours, including prostate cancer (24). Because ERK is primarily activated via phosphorylation $(39,40)$, the level of ERK phosphorylation in PCa cells after CDCA5 knockdown was examined in vivo and in vitro. Notably, once CDCA5 was suppressed, the phosphorylation level of ERK was significantly reduced, and the activity of this signalling pathway was diminished. In addition, it was revealed that patients with prostate cancer with high CDCA5 levels also had high levels of ERK phosphorylation. This again confirms that CDCA5 promotes prostate cancer progression through the ERK signalling pathway. In addition to the ERK signalling pathway, researchers revealed that CDCA5 could also inhibit the apoptosis of liver cancer cells through the AKT signaling pathway (41); CDCA5 could regulate cyclin E1 to affect the progression of gastric cancer (29); CDCA5 promoted bladder cancer cell proliferation by upregulating two key cell-cycle factors, cell division cycle protein 2 (CDC2) and cyclin B1, and by activating the PI3K/AKT/mTOR pathway (42). These signalling pathways may become the direction of follow-up progress in this research.

In conclusion, it was demonstrated that CDCA5 was highly expressed in PCa tissues and that its upregulated expression was significantly associated with poor outcomes. In vitro and in vivo studies revealed that CDCA5 knockdown induced $\mathrm{G} 2 / \mathrm{M}$ phase arrest and inhibited PCa cell growth. In addition, targeted silencing of CDCA5 expression by PCa reduced the activity of the ERK signalling pathway, thereby inhibiting disease progression. In summary, CDCA5 is anticipated to be an important indicator for the early diagnosis and prognosis of prostate cancer. We will further explore its role in the development and progression of prostate cancer, thus providing more insight and new targets for the clinical diagnosis and treatment of prostate cancer. The present study also has some limitations. For example, the number of specimens was not large enough; the specific mechanism of CDCA5 and the ERK signalling pathway was not explored; and the upstream and downstream proteins of CDCA 5 have not been explored in depth. In followup research, these shortcomings will be addressed. 
In conclusion, CDCA5 was upregulated and affected the prognosis in patients with PCa. Decreased expression of CDCA5 inhibited PCa cell proliferation by inhibiting the ERK signalling pathway. Consequently, CDCA5 may be a potential therapeutic target for $\mathrm{PCa}$.

\section{Acknowledgements}

Not applicable.

\section{Funding}

The present stuy was supported by the National Natural Science Foundation of China (grant nos. 81872100 and 81772756) and the Natural Science Foundation of Tianjin (grant nos. 17JCZDJC35300, 17JCYBJC26000 and 18JCZDJC34800).

\section{Availability of data and materials}

The data used or analysed during the current study are available from the corresponding author upon reasonable request.

\section{Authors' contributions}

TS, ZS and YN designed the experiments. JJ and YaL performed the molecular biology experiments. JJ and YiL performed the animal experiments and participated in the sequence alignment. TS performed the statistical analysis. TS, YaL and JJ analysed the data and wrote the manuscript. All the authors read and approved the final manuscript.

\section{Ethics approval and consent to participate}

The present study was approved by the Medical Ethics Committee of The Second Hospital of Tianjin Medical University, Tianjin, China (nos. KY2019K107 and YN2019Y99). For the collection of clinical patient samples, written informed consent was obtained from all patients. All studies were conducted in accordance with the Declaration of Helsinki. The Ethics approval no. KY2019K107 was used for human samples and the Ethics approval no. YN2019Y99 was used for animal experiments.

\section{Patient consent for publication}

Not applicable.

\section{Competing interests}

The authors declare that they have no competing interests.

\section{References}

1. Siegel RL, Miller KD and Jemal A: Cancer Statistics, 2017. CA Cancer J Clin 67: 7-30, 2017.

2. Siegel RL, Miller KD and Jemal A: Cancer statistics, 2018. CA Cancer J Clin 68: 7-30, 2018.

3. Zhang $\mathrm{N}$ and Pati D: Sororin is a master regulator of sister chromatid cohesion and separation. Cell Cycle 11: 2073-2083, 2012.

4. Zhang N and Pati D: Handcuff for sisters: A new model for sister chromatid cohesion. Cell Cycle 8: 399-402, 2009.
5. Zhang N, Panigrahi AK, Mao Q and Pati D: Interaction of Sororin protein with polo-like kinase 1 mediates resolution of chromosomal arm cohesion. J Biol Chem 286: 41826-41837, 2011.

6. Yeh CR, Hsu I, Song W, Chang H, Miyamoto H, Xiao GQ, Li L, Yeh S: Fibroblast ERalpha promotes bladder cancer invasion via increasing the CCL1 and IL-6 signals in the tumor microenvironment. Am J Cancer Res 5: 1146-1157, 2015.

7. Nguyen MH, Koinuma J, Ueda K, Ito T, Tsuchiya E, Nakamura Y and Daigo Y: Phosphorylation and activation of cell division cycle associated 5 by mitogen-activated protein kinase play a crucial role in human lung carcinogenesis. Cancer Res 70: 5337-in vivo5347, 2010.

8. Chen H, Chen J, Zhao L, Song W, Xuan Z, Chen J, Li Z, Song G, Hong L, Song P, et al: CDCA5, Transcribed by E2F1, promotes oncogenesis by enhancing cell proliferation and inhibiting apoptosis via the AKT pathway in hepatocellular carcinoma. J Cancer 10: 1846-1854, 2019.

9. Shen Z, Yu X, Zheng Y, Lai X, Li J, Hong Y, Zhang H, Chen C, $\mathrm{Su} \mathrm{Z}$ and Guo R: CDCA5 regulates proliferation in hepatocellular carcinoma and has potential as a negative prognostic marker. OncoTargets Ther 11: 891-901, 2018.

10. Shen A, Liu L, Chen H, Qi F, Huang Y, Lin J, Sferra TJ, Sankararaman S, Wei L, Chu J, et al: Cell division cycle associated 5 promotes colorectal cancer progression by activating the ERK signaling pathway. Oncogenesis 8: 19, 2019.

11. Wang L, Tang H, Thayanithy V, Subramanian S, Oberg AL, Cunningham JM, Cerhan JR, Steer CJ and Thibodeau SN: Gene networks and microRNAs implicated in aggressive prostate cancer. Cancer Res 69: 9490-9497, 2009.

12. Li HY, Jin N, Han YP and Jin XF: Pathway crosstalk analysis in prostate cancer based on protein-protein network data. Neoplasma 64: 22-31, 2017.

13. Tolkach Y, Merseburger A, Herrmann T, Kuczyk M, Serth J and Imkamp F: Signatures of adverse pathological features, androgen insensitivity and metastatic potential in prostate cancer. Anticancer Res 35: 5443-5451, 2015.

14. Burotto M, Chiou VL, Lee JM and Kohn EC: The MAPK pathway across different malignancies: A new perspective. Cancer 120: 3446-3456, 2014.

15. Kim EK and Choi EJ: Compromised MAPK signaling in human diseases: An update. Arch Toxicol 89: 867-882, 2015.

16. Bolden A, Bernard L, Jones D, Akinyeke T and Stewart LV: The PPAR gamma agonist troglitazone regulates Erk 1/2 phosphorylation via a PPARgamma-independent, MEK-dependent pathway in human prostate cancer cells. PPAR Res 929052: 2012, 2012.

17. Caraglia M, Marra M, Leonetti C, Meo G, D'Alessandro AM, Baldi A, Santini D, Tonini G, Bertieri R, Zupi G, et al: R115777 (Zarnestra)/Zoledronic acid (Zometa) cooperation on inhibition of prostate cancer proliferation is paralleled by Erk/Akt inactivation and reduced Bcl-2 and bad phosphorylation. J Cell Physiol 211: 533-543, 2007.

18. Wang J, Xia C, Pu M, Dai B, Yang X, Shang R, Yang Z, Zhang R, Tao K and Dou K: Silencing of CDCA5 inhibits cancer progression and serves as a prognostic biomarker for hepatocellular carcinoma. Oncol Rep 40: 1875-1884, 2018.

19. Tang Z, Li C, Kang B, Gao G, Li C and Zhang Z: GEPIA: A web server for cancer and normal gene expression profiling and interactive analyses. Nucleic Acids Res 45 (W1): W98-W102, 2017.

20. Cooper LA, Demicco EG, Saltz JH, Powell RT, Rao A and Lazar AJ: PanCancer insights from The Cancer Genome Atlas: The pathologist's perspective. J Pathol 244: 512-524, 2018.

21. Livak KJ and Schmittgen TD: Analysis of relative gene expression data using real-time quantitative PCR and the 2(-Delta Delta C(T)). Methods Methods 25: 402-408, 2001.

22. Shen T, Li Y, Zhu S, Yu J, Zhang B, Chen X, Zhang Z, Ma Y, Niu Y and Shang Z: YAP1 plays a key role of the conversion of normal fibroblasts into cancer-associated fibroblasts that contribute to prostate cancer progression. J Exp Clin Cancer Res 39: 36, 2020.

23. Bai L, Ren Y and Cui T: Overexpression of CDCA5, KIF4A, $T P X 2$, and FOXM1 coregulated cell cycle and promoted hepatocellular carcinoma development. J Comput Biol 27: 965-974, 2020.

24. Xu B, Wang N, Wang X, Tong N, Shao N, Tao J, Li P, Niu X, Feng N, Zhang L, et al: MiR-146a suppresses tumor growth and progression by targeting EGFR pathway and in a p-ERKdependent manner in castration-resistant prostate cancer. Prostate 72: 1171-1178, 2012. 
25. Lopez-Lazaro M: The stem cell division theory of cancer. Crit Rev Oncol Hematol 123: 95-113, 2018.

26. Boeynaems S, Tompa P and Van Den Bosch L: Phasing in on the cell cycle. Cell Div 13: 1, 2018.

27. Wang YC, Chang KC, Lin BW, Lee JC, Lai CH, Lin LJ, Yen Y, Lin CS, Yang SJ, Lin PC, et al: The EGF/hnRNP Q1 axis is involved in tumorigenesis via the regulation of cell cycle-related genes. Exp Mol Med 50: 1-14, 2018.

28. Lu J, Lin JX, Zhang PY, Sun YQ, Li P, Xie JW, Wang JB, Chen QY, Cao LL, Lin Y, et al: CDK5 suppresses the metastasis of gastric cancer cells by interacting with and regulating PP2A. Oncol Rep 41: 779-788, 2019.

29. Zhang Z, Shen M and Zhou G: Upregulation of CDCA5 promotes gastric cancer malignant progression via influencing cyclin E1. Biochem Biophys Res Commun 496: 482-489, 2018.

30. Schmitz J, Watrin E, Lenart P, Mechtler K and Peters JM: Sororin is required for stable binding of cohesin to chromatin and for sister chromatid cohesion in interphase. Curr Biol 17: 630-636, 2007.

31. Nishiyama T, Ladurner R, Schmitz J, Kreidl E, Schleiffer A, Bhaskara V, Bando M, Shirahige K, Hyman AA, Mechtler K, et al: Sororin mediates sister chromatid cohesion by antagonizing Wapl. Cell 143: 737-749, 2010.

32. Rankin S, Ayad NG and Kirschner MW: Sororin, a substrate of the anaphase-promoting complex, is required for sister chromatid cohesion in vertebrates. Mol Cell 18: 185-200, 2005.

33. Feng W, Cai D, Zhang B, Lou G and Zou X: Combination of HDAC inhibitor TSA and silibinin induces cell cycle arrest and apoptosis by targeting survivin and cyclinB1/Cdk1 in pancreatic cancer cells. Biomed Pharmacother 74: 257-264, 2015.

34. Li P, Jia YF, Ma XL, et al: DEC2 suppresses tumor proliferation and metastasis by regulating ERK/NF-kappaB pathway in gastric cancer. Am J Cancer Res 6: 1741-1757, 2016.

35. Zhang L, Mao Y, Mao Q, Fan W, Xu L, Chen Y, Xu L and Wang J: FLOT1 promotes tumor development, induces epithelial-mesenchymal transition, and modulates the cell cycle by regulating the Erk/Akt signaling pathway in lung adenocarcinoma. Thorac Cancer 10: 909-917, 2019.
36. Li ZH, Li L, Kang LP and Wang Y: MicroRNA-92a promotes tumor growth and suppresses immune function through activation of MAPK/ERK signaling pathway by inhibiting PTEN in mice bearing U14 cervical cancer. Cancer Med 7: 3118-3131, 2018.

37. Wang S, Huang X, Li Y, Lao H, Zhang Y, Dong H, Xu W, Li JL and Li M: RN181 suppresses hepatocellular carcinoma growth by inhibition of the ERK/MAPK pathway. Hepatology 53: 1932-1942, 2011.

38. Mu X, Shi W, Xu Y, Xu C, Zhao T, Geng B, Yang J, Pan J, Hu S, Zhang $\mathrm{C}$, et al: Tumor-derived lactate induces M2 macrophage polarization via the activation of the ERK/STAT3 signaling pathway in breast cancer. Cell Cycle 17: 428-438, 2018.

39. Kumari G and Mahalingam S: Extracellular signal-regulated kinase 2 (ERK-2) mediated phosphorylation regulates nucleocytoplasmic shuttling and cell growth control of Ras-associated tumor suppressor protein, RASSF2. Exp Cell Res 315: 2775-2790, 2009.

40. Zhang Y,Zhang GL, Sun X, Cao KX, Shang YW, Gong MX, Ma C, Nan N, Li JP, Yu MW, et al: Gubenyiliu II inhibits breast tumor growth and metastasis associated with decreased heparanase expression and phosphorylation of ERK and AKT pathways. Molecules 22: 787, 2017. doi: 10.3390/molecules22050787.

41. Tian Y, Wu J, Chagas C, Du Y, Lyu H, He Y, Qi S, Peng Y and Hu J: CDCA5 overexpression is an indicator of poor prognosis in patients with hepatocellular carcinoma (HCC). BMC Cancer 18: 1187, 2018.

42. Fu G, Xu Z, Chen X, Pan H, Wang Y and Jin B: CDCA5 functions as a tumor promoter in bladder cancer by dysregulating mitochondria-mediated apoptosis, cell cycle regulation and PI3k/ AKT/mTOR pathway activation. J Cancer 11: 2408-2420, 2020.

(7) $\Theta$ This work is licensed under a Creative Commons Attribution-NonCommercial-NoDerivatives 4.0 International (CC BY-NC-ND 4.0) License. 